\title{
VALIDADE DA ESCALA DE ESTÁGIOS DE MUDANÇA
}

\author{
VALIDITY OF THE STAGES OF CHANGE SCALES
}

\author{
Elisa Medici Pizão YOSHIDA ${ }^{1}$ \\ Ricardo PRIMI² \\ Rosália PACE ${ }^{3}$
}

\begin{abstract}
RESUMO
O estudo, com amostra clínica ( $N=147)$, apresenta a consistência interna, estrutura fatorial, validade concorrente e preditiva da versão em português da Escala de Estágios de Mudança-EEM. As propriedades psicométricas da escala, um instrumento de tipo auto-relato e 32 itens, são comparadas às de dois estudos com a versão em inglês. Os resultados apontam uma estrutura fatorial compatível com a versão original, que avalia quatro estágios de mudança: pré-contemplação, contemplação, ação e manutenção. Adaptações de ao menos quatro itens dos estágios de pré-contemplação e contemplação são necessárias para aumentar os coeficientes de consistência interna, inferiores aos dos estudos originais. A fraca associação entre a EEM e a Escala Diagnóstica Adaptativa Operacionalizada-Redefinida-EDAO-R sugere a inadequação do critério para a validade convergente. Com base nos escores da EEM, os resultados não permitem predizer quais pacientes têm mais chance de concluir psicoterapias breves. Sugere-se a continuidade das pesquisas.
\end{abstract}

Palavras-chave: modelo transteórico de mudança; avaliação clínica; psicoterapia breve.

(1) É Psicóloga Docente do Programa de Pós-Graduação em Psicologia e do curso de graduação em Psicologia da Pontifícia Universidade Católica de Campinas.

Endereço para correspondência: Av. Francisco de Assis Dinis, 227, CEP 06030-380, Osasco, SP. Tel/Fax: (011)3684-1497 E-mail: eyoshida.tln@terra.com.br

(2) É Psicólogo, Doutor em Psicologia Escolar e do Desenvolvimento Humano pela Universidade de São Paulo com parte desenvolvida na Yale University (EUA). Docente do Curso de Graduação e do Mestrado em Psicologia da Universidade São Francisco/Itatiba.

(3) É Psicóloga, Mestre em Psicologia Clínica pela Pontifícia Universidade Católica de Campinas, doutoranda do Programa de Pós-Graduação em Psicologia da Pontifícia Universidade Católica de Campinas. Psicóloga do Hospital Heliópolis. 


\begin{abstract}
The study, with a clinical sample $(N=147)$, presents the internal consistency, factorial structure, concurrent and predictive validities of the Portuguese version of the Stages of Change Scales-SCS. The psychometric properties of the scales, a 32 item self-report instrument, are compared to those of two studies with the English version. Results point to a factorial structure compatible with that of the original version, which evaluates four stages of change: precontemplation, contemplation, action and maintenance. Adaptations, of at least four items of the precontemplation and contemplation stages, are required to improve the internal consistency coefficients, lower than those of the original studies. The weak association between the SCS and the Escala Diagnóstica Adaptativa Operacionalizada-Redefinida - EDAO- $R$ suggests the criterion unsuitability to the concurrent validity. Based on the SCS scores, results do not allow to predict which patients are more suitable to conclude brief psychotherapies. New researches are suggested.
\end{abstract}

Key words: transtheoretical model of change; clinical assessment; brief psychotherapy.

\section{INTRODUÇÃO}

Poder predizer quais pacientes têm maior chance de aderir à psicoterapia e de responder a ela com mudanças evidentes tem sido um dos objetivos dos diferentes sistemas de psicoterapia. A despeito de todos os esforços até aqui empreendidos, são usualmente altos os índices de abandono. Efetivamente, já em 1986, Garfield indicava que $70 \%$ dos pacientes de clínicas públicas abandonam o tratamento antes da décima sessão. Com o propósito de fazer face a este problema, a Terapia Transteórica foi especificamente desenvolvida. Ela se baseia no chamado Modelo Transteórico de Mudança, ou TMC (sigla em inglês), que compreende conceitos empiricamente desenvolvidos a respeito de como as pessoas mudam. Dentre eles o principal é o conceito de estágios de mudança que, em conjunto com os processose os níveis de mudança, integra as chamadas dimensões de mudança (veja por exemplo: Prochaska, 1995, Prochaska \& Norcross, 1999).

Apesar de existirem escalas específicas para a avaliação dos processos (Prochaska, Velicer, DiClemente \& Fava, 1988) e níveis de mudança (Norcross, Prochaska \& Hambrecht, 1985), aqui se focaliza apenas a destinada à avaliação dos estágios. Neste sentido, apresenta-se a seguir um resumo das definições dos estágios encontradas em Prochaska (1995).

A idéia associada a estágios é a de que a mudança ocorre ao longo do tempo, sendo que sua natureza encerra ao mesmo tempo um caráter dinâmico e estável, traduzível em estágios específicos assim designados: pré-contemplação, contemplação, preparação, ação, manutenção e término.

No estágio de pré-contemplação não aparece ainda a intenção de mudança. O sujeito não apresenta a consciência de que há um problema a ser enfrentado. Dificilmente procura por psicoterapia e quando o faz, encontra-se usualmente pressionado por outras pessoas (familiares, patrão, autoridades judiciais, entre outros). A característica principal deste estágio seria, portanto, a resistência em reconhecer ou modificar um problema ou um padrão comportamental.

No estágio de contemplação já aparece a consciência de que há um problema e o sujeito pensa seriamente em enfrentá-lo, mas nenhum 
esforço efetivo é feito neste sentido. Dependendo da situação, pode permanecer por um longo período de tempo neste estágio.

Entre o estágio de contemplação e o de ação pode interpor-se o estágio de preparação. Nele, verificam-se algumas iniciativas para a mudança que não chegam a ser efetivas. $\mathrm{Na}$ maioria das vezes o sujeito neste estágio já fez mais de uma tentativa de mudança, sem sucesso.

O enfrentamento da situação-problema ocorre no estágio chamado de ação, que requer um esforço efetivo em termos de tempo e de energia para superá-la. Aqui, as tentativas para a mudança são evidentes e o sujeito tende a receber a aprovação e o reconhecimento externos pelos seus esforços.

É importante frisar que o sujeito tem que não apenas modificar seu comportamento ou atitude mas mantê-lo durante um período de tempo razoável. Neste sentido, todos os esforços para impedir o retorno aos padrões anteriores e para consolidar os ganhos caracterizam o estágio de manutenção.

Há naturalmente certos padrões de comportamento que demandam manutenção durante toda a vida, posto que implicam contínuo esforço para sua estabilidade e para a não ocorrência de recaídas. As características principais do estágio de manutenção seriam a estabilidade do novo padrão de conduta e a ausência de recaídas, à custa de um esforço contínuo por parte do sujeito.

Considera-se que se atinge o estágio de término quando a situação-problema foi totalmente superada e há a confiança de que o antigo padrão não deve retornar.

Deve-se salientar que o progresso nos estágios não costuma se dar de forma linear, sendo que as recaídas e o retorno aos padrões antigos de comportamento são os mais freqüentes. A mudança ocorre, usualmente, através de um movimento em espiral em que o retorno a estágios iniciais é antes a regra do que a exceção. Esta observação remete à idéia de que o movimento de progressão dos estágios encontra-se provavelmente condicionado a outras variáveis que podem facilitá-lo, retardá-lo ou mesmo agirem como forças impeditivas.

O presente estudo teve como objetivo estimar a consistência interna, estrutura fatorial, validade convergente e preditiva da versão em português da Escala de Estágios de MudançaEEM (McConnaughy, Prochaska \& Velicer,1983), quando aplicada à população clínica. As propriedades psicométricas obtidas são comparadas às de dois estudos realizados com a versão original da escala: o de McConnaughy e cols. (1983) e o de McConnaughy, DiClemente, Prochaska e Velicer (1989).

Dentre outras medidas que poderiam ser utilizadas como critério da EEM, por eventualmente apresentarem relação com os estágios de mudança, destacou-se, para esta pesquisa, a eficácia da adaptação conforme definida por Simon (1989).

Considerou-se que, em uma situação de busca por psicoterapia, uma associação positiva entre a qualidade da adaptação e os estágios de mudança poderia constituir evidência de validade convergente da EEM. Sendo assim, utilizou-se a Escala Diagnóstica Adaptativa Operacionalizada-Redefinida - EDAO-R (Simon, 1997) como medida de critério, já que pesquisa anterior indicou a validade desta escala junto à população estudada (Yoshida, 1999).

Para a estimativa da validade preditiva da EEM, utilizou-se como critério externo o fato de o sujeito concluir ou interromper o atendimento psicoterápico breve. Aidéia era que a progressão nos estágios se dá pelo empenho do paciente em fazer face às suas dificuldades. $E$, deste modo, a persistência até o final do processo deveria, ao menos teoricamente, associar-se positivamente com os estágios de mudança observados no momento em que ele buscou ajuda psicoterapêutica. 


\section{MÉTODO}

\section{Participantes}

Integraram a amostra 147 adultos, que buscaram atendimento psicológico em uma instituição da cidade de São Paulo dedicada ao ensino e pesquisa em psicoterapia breve psicodinâmica. Do total da amostra, 23\% eram do sexo masculino e $77 \%$ do feminino, com idades variando entre 17 e 65 anos ( $M=33,7$, DP = 11). Quanto ao estado civil, $49,7 \%$ eram solteiros; $34,7 \%$ casados ou amasiados; $8,8 \%$ separados; desquitados ou divorciados; $4,1 \%$ viúvos e 2,7\% não informaram o estado civil. Quanto à escolaridade, predominaram os com $2^{\circ}$ grau completo $(33,3 \%)$, seguidos dos com $3^{\circ}$ grau completo $(27,9 \%)$ e $3^{\circ}$ grau incompleto $(22,4 \%), 1^{\circ}$ grau incompleto $(8,8 \%), 1^{\circ}$ grau completo $(2,0 \%)$ e finalmente, os com $2^{\circ}$ grau incompleto $(4,1 \%)$.

Quanto ao atendimento prestado, 63 participantes foram atendidos em PBP na instituição, sendo que 23,8\% concluíram e 19\% interromperam antes da sessão de término acordada com o terapeuta; $10,9 \%$ foram encaminhados para outra instituição logo após a triagem; $4,8 \%$ desistiram após a triagem e sobre $41,5 \%$ dos casos não há informações.

\section{Medidas de avaliação}

Escala de Estágios de Mudança- EEM (McConnaughy e cols., 1983) - É uma medida de auto-avaliação constituída por 32 itens divididos em quatro grupos de oito itens correspondentes aos seguintes estágios de mudança: pré-contemplação, contemplação, ação e manutenção. Para cada item são apresentadas possibilidades de respostas em escala de tipo Likert de cinco pontos que variam desde discordo totalmente até concordo totalmente. A definição do estágio de mudança é dada pela maior pontuação nos itens de um determinado estágio.
A tradução para o português (Pace, 1999) foi realizada por tradutor juramentado com base na versão constante em McConnaughy e cols. (1989).

Um primeiro estudo com a versão original (McConnaughy e cols., 1983), envolvendo uma amostra de 155 participantes em que se procedeu à análise fatorial dos itens, demonstrou que os quatro primeiros componentes explicavam $58 \%$ da variância total. Em relação à consistência interna, foram os seguintes os valores dos coeficientes alpha: 0,88 para o estágio de pré-contemplação, 0,88 para o de contemplação, 0,89 para o de ação e 0,88 para o de manutenção. Considera-se que a escala avalie a prontidão dos pacientes para se envolver em mudança no início de processos de terapia.

Uma segunda pesquisa de validação, envolvendo amostra clínica de 327 participantes, replicou os resultados já mencionados. Quatro distintos fatores explicaram $45 \%$ da variância total e os coeficientes alpha de Cronbach foram os seguintes: pré-contemplação, 0,79 ; contemplação, 0,84; ação, 0,84 e manutenção, 0,82 (McConnaughy e cols., 1989).

Escala Diagnóstica Adaptativa Operacionalizada Redefinida - EDAO - R (Simon, 1997). Esta versão permite uma avaliação quantitativa e outra qualitativa da eficácia da adaptação, a partir de entrevista clínica. A avaliação quantitativa decorre da avaliação da qualidade da adaptação em dois setores da personalidade, Afetivo-Relacional (AR) e Produtividade ( $\mathrm{Pr}$ ). Cada um deles pode ser considerado: adequado, pouco adequado ou pouquíssimo adequado, por atender ou não a cada um dos seguintes critérios: 1 . Fornecer solução ao problema, 2. Satisfazer o sujeito, 3. Gerar conflito intrapsíquico e/ou ambiental. Uma vez avaliado cada um dos setores tem-se cinco grupos de adaptação possíveis: Adaptação eficaz (Gr. 1); Adaptação Ineficaz, seguida da qualificação grupal: Leve (Gr. 2); Moderada (Gr. 3); Severa (Gr. 4); Grave (Gr. 5). Nos casos de crise acrescenta-se esta designação ao grupo adaptativo. Ex.: adaptação eficaz em crise ou 
Gr. 1- C. Quanto à avaliação qualitativa, inclui a avaliação da qualidade da adaptação nos setores Sociocultural (SC) e Orgânico (Or), além da avaliação dos outros dois já mencionados: Are Pr.

A pesquisa que estimou a precisão e validade desta escala junto à população desta pesquisa (Yoshida, 1999) contou com 100 participantes, dos quais 50 concluíram e 50 interromperam as psicoterapias breves. Indicou boa precisão tanto para a avaliação da configuração geral da escala ( kappa $=0,78$ ), quanto para cada setor da personalidade: $A R$, $\mathrm{k}=0,73$ e $\mathrm{Pr}, \mathrm{k}=1$. Como medida de validade concorrente obteve associação significante entre a EDAO-R e a Escala de Avaliação Psicodinâmica - EAP (Husby, 1985) para os que concluíram os atendimentos, $r_{s}(48)=0,50$, $p=0,05$. Como medida de validade preditiva obteve a associação significante entre $\mathrm{EDDAO}$ R, realizada no início das psicoterapias, e a qualidade dos atendimentos avaliada pela Escala de Resultados de Sifneos (1987/1989), $r_{s}(48)=0,34$, $p=0,05$.

\section{Instituição}

A pesquisa foi realizada com pacientes que buscaram atendimento numa instituição de formação de psicoterapeutas em psicoterapia psicodinâmica breve que funcionou entre 1987 e 2000, na cidade de São Paulo.

De acordo com a rotina, o paciente passava inicialmente por uma entrevista realizada por um dos supervisores ou por alunos dos segundose terceiros anos do curso de formação, para verificar se reunia condições mínimas para o atendimento psicoterápico breve. Os critérios de aceitação eram bastante amplos, tendo-se apenas alguns critérios gerais de contra-indicação: pacientes em surto psicótico, fármaco-dependentes, alcoolistas ou pessoas que buscam o atendimento com a intenção de modificar sua orientação sexual (usualmente homossexuais), pacientes com tentativa prévia de suicídio, ou com comporta- mentos claramente auto ou heterodestrutivos (Malan, 1976/1981).

A entrevista inicial buscava focalizar o motivo da busca do atendimento, as principais dificuldades do paciente, explorando os motivos que teriam dado origem à situação atual ou, ao menos, os episódios a que o paciente associava suas dificuldades. Sempre que possível, procurava-se obter dados relacionados aos quatro setores da personalidade de acordo com Simon (1989;1997): Afetivo Relacional (AR), Produtividade (Pr), Sociocultural (SC) e Orgânico (Or).

Quanto à duração, a entrevista variava entre 20 a 50 minutos, sendo o mais freqüente entrevistas de 30 minutos. Ao término, o psicólogo comunicava ao paciente se seria possível o seu atendimento na instituição. Em caso afirmativo, fornecia informações sobre o atendimento; caso contrário, encaminhava-o para outra instituição, onde considerava que o paciente seria melhor atendido (em geral, instituições que atendem dependentes de drogas, psicóticos ou que fornecem atendimento de longo prazo).

Quando aceito, o paciente passava por um processo psicoterapêutico conduzido por um dos profissionais em formação, que podiam ser psicólogos ou médicos, embora estes últimos fossem em número mais reduzido. O processo tinha duração média de 12 sessões semanais, podendo chegar a 17 ou 18 sessões em alguns casos. Uma entrevista de acompanhamento, realizada em média três meses após o término, era usualmente proposta.

\section{Procedimento}

Quando o paciente chegava para a primeira entrevista, além de preencher o formulário de rotina com dados pessoais (nome, idade, profissão, filiação, e pessoa ou instituição que o encaminhara), era solicitado a responder à EEM. Quando concordava, era encaminhado a uma sala para responder ao instrumento. Em seguida, era chamado pelo psicólogo para a entrevista de triagem, ao final da qual podia ser encaminhado para PBP na instituição ou para outra, quando não atendia aos critérios de indicação. Neste 
momento era também realizada a avaliação da eficácia adaptativa, utilizando-se os critérios da EDAO-R.

Para a estimativa da validade preditiva considerou-se, como, medida de critério, o fato de o participante ter concluído ou não a psicoterapia. Em cada caso, verificou-se o contrato estabelecido com o terapeuta quanto à data limite do atendimento, e às sessões realizadas. A coleta de dados se deu ao longo dos anos de 1999 e 2000.

\section{RESULTADOS}

De acordo com os objetivos, os resultados obtidos foram comparados aos dos estudos de McConnaughy e cols. (1983) e McConnaughy e cols. (1989), doravante chamados respectivamente de Estudo 1 e Estudo 2.

Cabe ressaltar que nos Estudos 1 e 2 a amostra era relativamente equilibrada quanto ao sexo, contrariamente à brasileira, em que prevaleceram as mulheres; mas não há diferença significante entre os estudos quanto à média das idades, em torno de 31 anos nos estudos originais. Quanto à escolaridade, eles não fornecem dados, mas é possível que se assemelhe à amostra do presente estudo, em que prevalecem os participantes com $2^{\circ}$ grau completo, seguidos dos com $3^{\circ}$ grau completo.

\section{Análise dos componentes principais}

A análise dos componentes principais mostrou a presença de dez componentes ou fatores com eigenvalue superiores a 1,0 que explicam 62,3\% da variância acumulada. Destes, apenas quatro obtiveram eigenvalue superiores a 1,5 correspondendo a 49,3\% da variância total. Como se pretendia proceder à comparação dos resultados com os dos Estudos 1 e 2, realizouse a rotação varimax dos itens considerando-se apenas os quatro primeiros fatores.

O primeiro componente contribuiu com 15,6\% da variância total e é integrado primordial- mente pelos itens do estágio de ação da versão original da escala. O segundo contribuiu com 9,3\% da variância e é representado principalmente pelos itens do estágio de manutenção, enquanto que o terceiro, com 7,5\% da variância, está relacionado ao estágio de contemplação e o quarto fator, com 5,9\% da variância total, possui a maioria dos itens do estágio de pré-contemplação.

Deve-se mencionar ainda que o primeiro fator revelou eigenvalue igual a 5,0, enquanto que os demais, respectivamente, 3,0, 2,4 e 1,9, o que indica uma menor importância relativa em termos de "comunalidade" dos fatores 3 e 4 em relação aos 1 e 2, o que pode comprometer a consistência interna destes fatores com menor número de indicadores precisos. Além disto, a análise do gráfico scree (Figura 1) sugere que um primeiro ponto para decisão sobre o número de fatores seria justamente no quarto componente.

Comparando-se o valor explicativo da variância total dos quatro primeiros fatores $(38,3 \%)$ com os dos Estudos 1 e 2 (respectivamente, $58 \%$ e $45 \%$ ), verifica-se que na versão em português os itens apresentam em geral uma menor covariância entre si, o que pode se refletir talvez em uma menor representatividade do constructo, apesar da rotação varimax com normalização Kaiser ter replicado grande parte dos resultados obtidos nos dois estudos originais, como se pode observar pelo exame da Tabela 1.

O ponto de corte para a retenção do item em um determinado componente foi 0,30 , tanto no presente estudo quanto nos estudos americanos. Na Tabela 1 são apresentados os itens de cada componente, acompanhados das cargas fatoriais verificadas no presente estudo assim como nos Estudos 1 e 2.

Observando a Tabela 1, verifica-se que sete dos oito itens relacionados ao estágio de pré-contemplação na escala original apresetaram cargas fatoriais acima de 0,30 no componente 4 . São eles: 1, 5, 13, 23, 26, 29 e 31. 
Deve-se destacar que os itens 5 e 13 apresentaram ainda correlação negativa com o componente do estágio de contemplação, respectivamente, com cargas $-0,34 \mathrm{e}-0,41$.

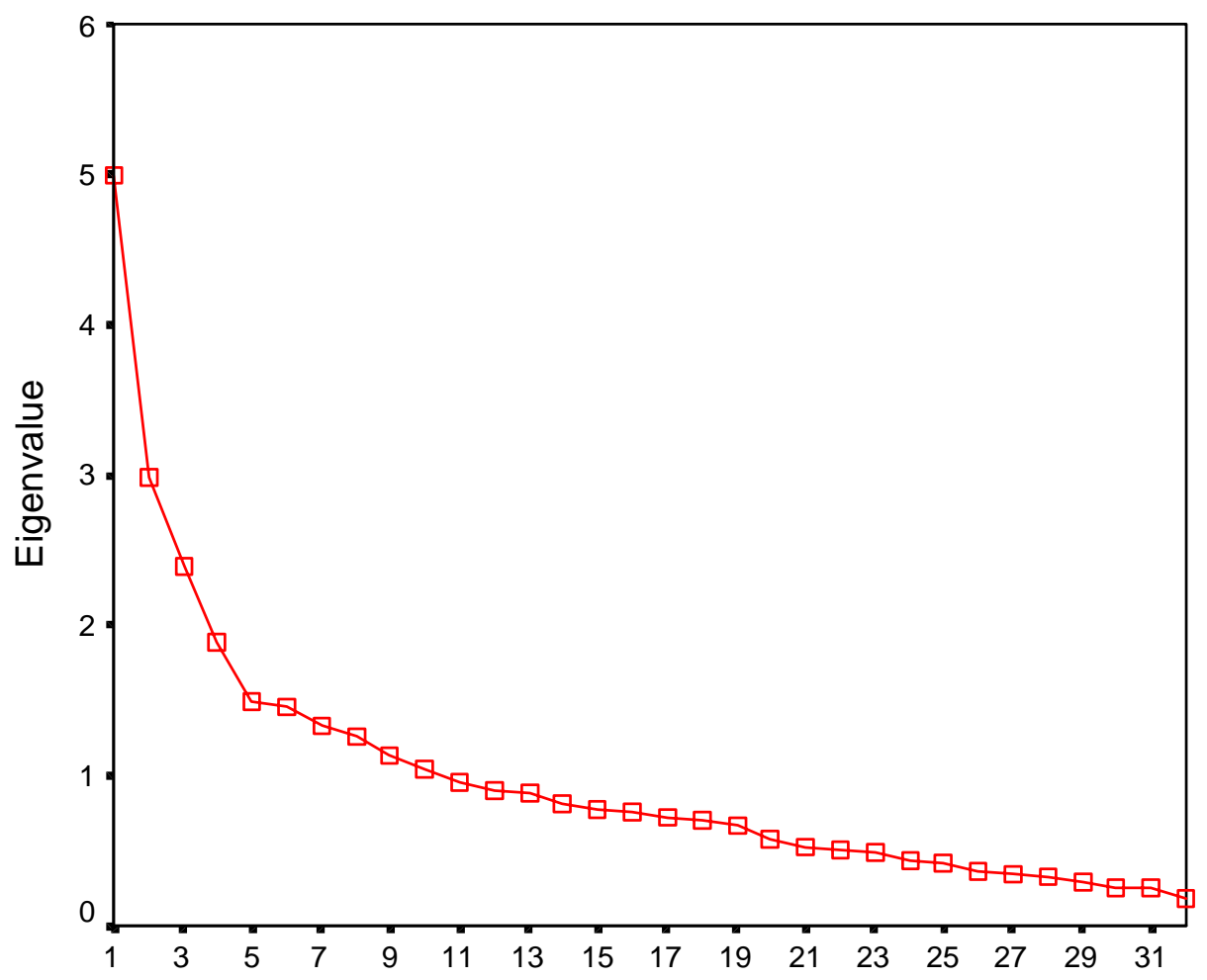

Figura 1. Distribuição dos eigenvalue segundo cada fator

O item 11 não se encontra representado neste componente, mas apresenta alta correlação negativa $(-0,42)$ com o de contemplação. Além disto, $87 \%$ da amostra assinalaram a alternativa discordo totalmente como resposta a ele, oque aponta para uma pequena sensibilidade às diferenças individuais neste estágio.

Quanto ao item 24, que na escala original está ligado ao estágio de contemplação, apresenta correlação elevada com componente da pré-contemplação $(0,40)$ e também com o de manutenção $(0,42)$, que neste estudo corresponde ao componente 2 .

Apenas cinco dos oito itens do estágio da contemplação dos estudos originais aparecem representados num mesmo componente (C 3), no presente estudo. São eles: 8, 12, 15, 19 e 21. Além disto, o item 20 , que na escala original representa o estágio de ação, também se encontra representado na contemplação $(0,48)$.

Quanto ao item 2, encontra-se representado no componente do estágio de ação (C1) e o 24 correlaciona-se tanto com os itens de manutenção (C2) quanto com os de pré-contemplação (C4), conforme já referido. $O$ item 4 não apresentou carga suficiente em nenhum dos quatro componentes.

Todos os itens da versão original do estágio de ação também se encontram representados num mesmo fator (C1). São eles: 3, 7, 10, 14, 17, 20, 25 e 30. Além deles, aparece o item 2 que corresponde ao componente do estágio de contemplação da escala original, como já referido. 


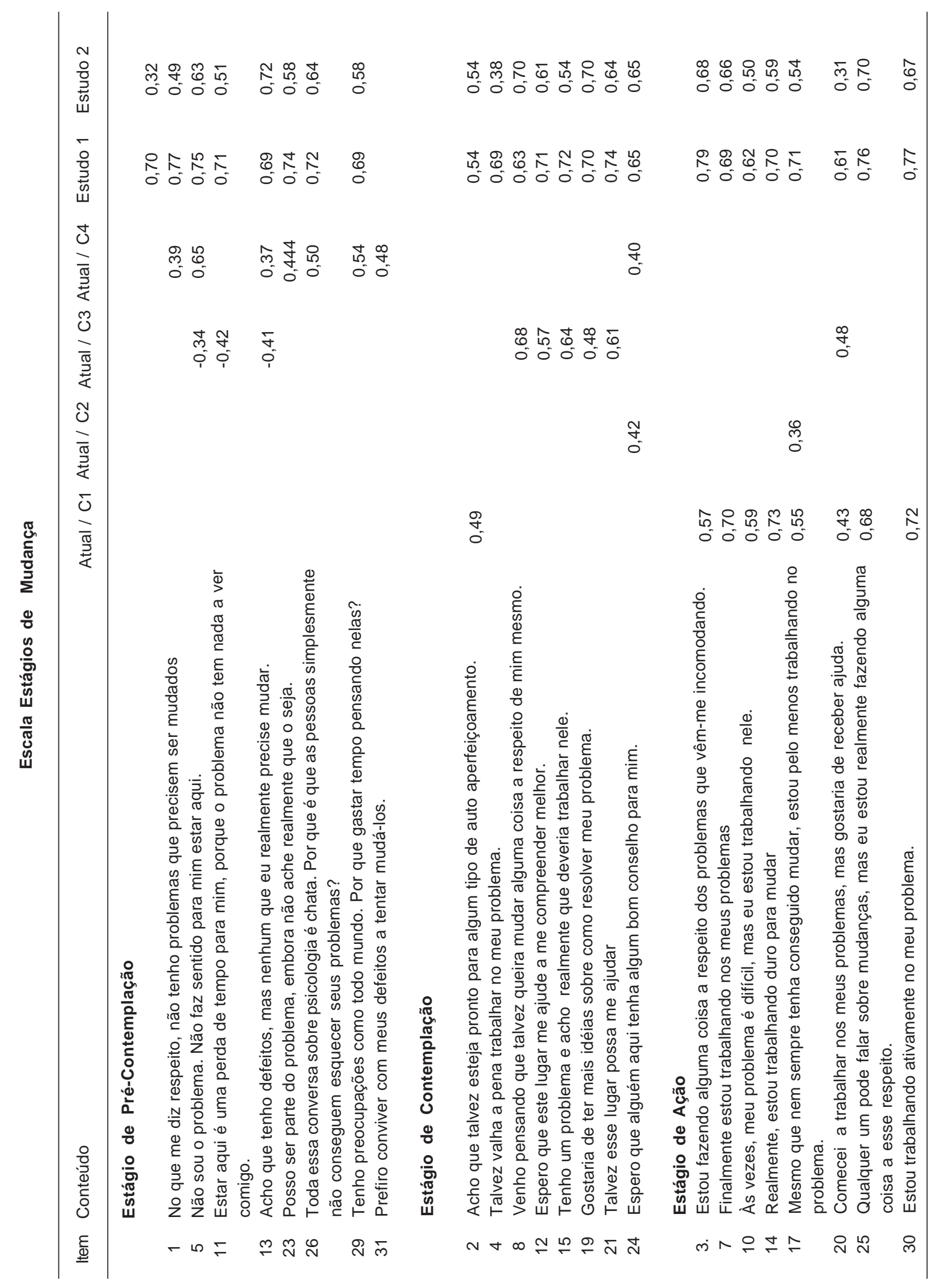

Rev. Estudos de Psicologia, PUC-Campinas, v. 20, n. 3, p. 7-21, setembro/dezembro 2003 


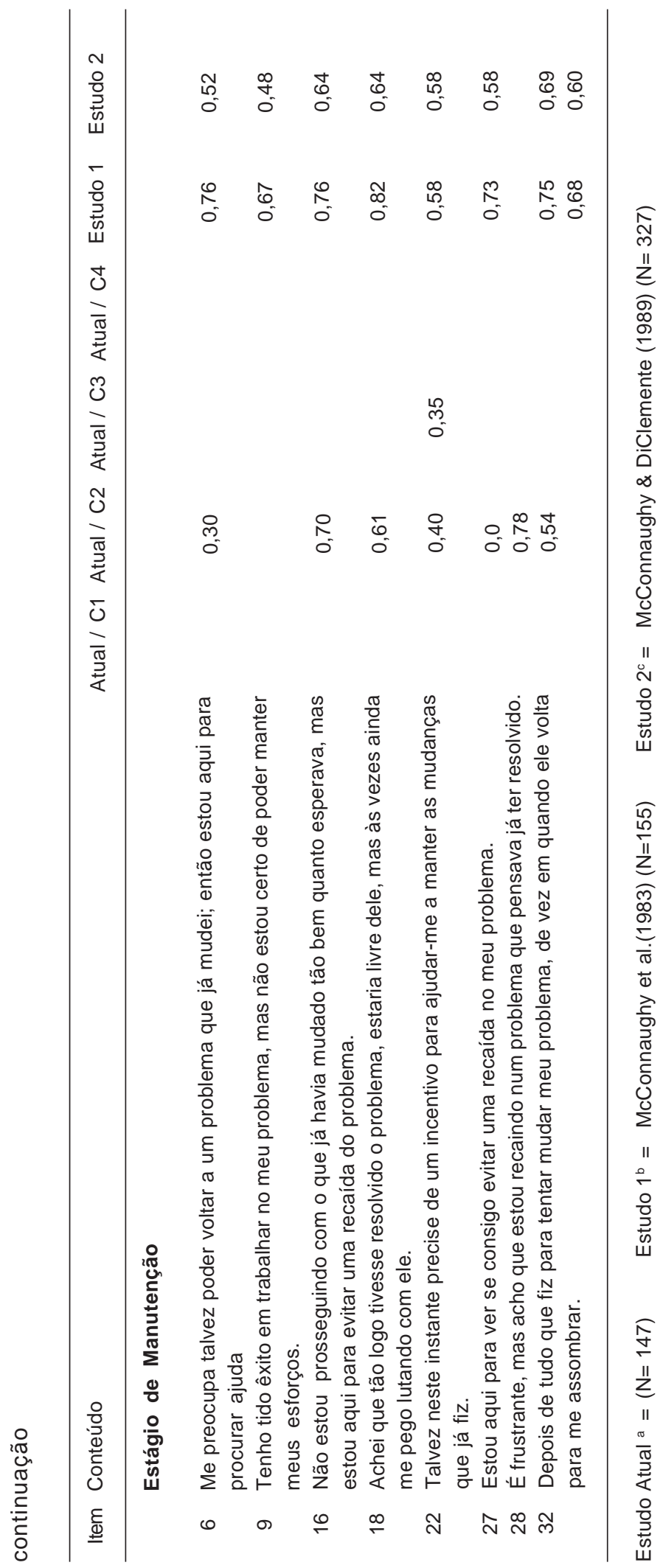

Rev. Estudos de Psicologia, PUC-Campinas, v. 20, n. 3, p. 7-21, setembro/dezembro 2003 
Sete dos oito itens do estágio de manutenção da escala original também se encontram num mesmo componente para a versão em português (C 2). Itens: 6, 16, 18, 22, 27, 28 e 32 . Quanto ao item 9, obteve carga fatorial insuficiente para ser retido $(0,26)$.

\section{Consistência Interna}

Os valores dos coeficientes alpha de Cronbach foram inferiores para os estágios de pré-contemplação e contemplação quando comparados aos de ação e manutenção, estes últimos mais próximos dos valores encontrados nos estudos anteriores, como se vê na Tabela 2.
Conforme referido anteriormente, os fatores pré-contemplação e contemplação são os que possuem menor eigenvalue, indicando covariância de menor magnitude entre os itens que o compõem, o que, por conseqüência, afeta a consistência interna.

\section{Médias, Desvios-Padrão e Coeficientes de Correlação de Pearson ( $r$ )}

Os valores das médias e dos desvios-padrão correspondentes a cada estágio (Tabela 3) são bastante semelhantes entre si nos três estudos, sugerindo que, apesar de eventuais diferenças entre as amostras, parece haver um padrão de respostas para populações clínicas.

Tabela 2. Coeficientes alpha de Cronbach segundo o estudo atuala e os estudos 1b e 2c.

\begin{tabular}{lccc}
\hline Estágio & Atual & Estudo 1 & Estudo 2 \\
\hline Pré-contemplação & 0,56 & 0,88 & 0,79 \\
Contemplação & 0,57 & 0,88 & 0,84 \\
Ação & 0,82 & 0,89 & 0,84 \\
Manutenção & 0,77 & 0,88 & 0,82 \\
\hline
\end{tabular}

Atual $^{\mathrm{a}}=(\mathrm{N}=133)$ Estudo $1^{\mathrm{b}}=$ McConnaughy et al. $(1983)(\mathrm{N}=155)$ Estudo $2^{\mathrm{c}}=$ McConnaughy \& DiClemente (1989) $(\mathrm{N}=293)$

Tabela 3. Médias e desvios padrões dos itens de cada estágio de mudança.

\begin{tabular}{|c|c|c|c|c|c|c|}
\hline \multirow{2}{*}{ Estágio } & \multicolumn{3}{|c|}{ M } & \multicolumn{3}{|c|}{ DP } \\
\hline & Estudo $1^{\mathrm{a}}$ & Estudo $2^{\mathrm{a}}$ & Atualc $^{c}$ & Estudo 1 & Estudo 2 & Atual \\
\hline Pré- Contemplação & $1,95^{d}$ & 2,02 & 1,90 & 0,698 & 0,666 & 10,59 \\
\hline Contemplação & 4,26 & 4,28 & 4,77 & 0,513 & 0,518 & 0,35 \\
\hline Ação & 3,92 & 3,91 & 3,95 & 0,643 & 0,615 & 0,73 \\
\hline Manutenção & 3,34 & 3,66 & 3,73 & 0,830 & 0,830 & 0,82 \\
\hline
\end{tabular}

Estudo $1^{\mathrm{a}}=$ McConnaughy et al.(1983) $(\mathrm{N}=155) \quad$ Estudo $2^{\mathrm{b}}=$ McConnaughy \& DiClemente $(1989)(\mathrm{N}=323)$ Atual $^{c}=(\mathrm{N}=133)$

$\mathrm{d}=$ as médias foram reproduzidas de tabela constante do Estudo 2, uma vez que no Estudo 1 a escala Likert estava revertida e portanto, 1 correspondia a concordo totalmente e 5, discordo totalmente. Neste sentido, no Estudo 1 aparece o reverso destes valores. 
Apesar de os coeficientes de correlação entre as subescalas terem ficado abaixo dos observados nos estudos anteriores (Tabela 4), verifica-se que eles são maiores entre as que medem estágios próximos entre si, como é o caso do de pré-contemplação e ação; ação e contemplação, ou ainda manutenção e ação. Nos demais casos a correlação ficou próxima de zero, refletindo a independência das medidas.

\section{Validade Concorrente}

Os coeficientes de correlação entre os estágios de mudança e as medidas da adequação da adaptação para os setores AR e PR (Tabela 5) indicam associação significante apenas entre o estágio ação e o setor da $\operatorname{Pr}$ (positiva). Nos demais casos estiveram próximas de zero, não se podendo afirmar nada sobre elas. Também para a configuração adaptativa geral, observou-se associação significante apenas com o estágio de ação.

\section{Validade Preditiva}

As médias, desvios-padrão, valores máximos e mínimos das respostas a cada uma das quatro escalas foram calculadas para os participantes que concluíram, os que interromperam as psicoterapias e para o total que recebeu atendimento na instituição. Os valores apresentados na Tabela 6 indicam padrões semelhantes de respostas para os dois grupos e para a amostra total, sendo impossível, com base na EEM, distingui-los.

Tabela 4. Coeficientes de correlação produto-momento de Pearson de cada estágio.

\begin{tabular}{|c|c|c|c|c|c|c|c|c|c|}
\hline \multirow{2}{*}{$\begin{array}{c}\text { Subes- } \\
\text { cala }\end{array}$} & \multicolumn{3}{|c|}{ Pré-Contemplação } & \multicolumn{3}{|c|}{ Contemplação } & \multicolumn{3}{|c|}{ Ação } \\
\hline & Estudo $1^{\mathrm{a}}$ & Estudo $2^{\mathrm{b}}$ & Atual $^{c}$ & Estudo 1 & Estudo 2 & Atual & Estudo 1 & Estudo 2 & Atual \\
\hline$P C^{d}$ & ----- & ----- & ----- & & & & & & \\
\hline C & $-0,45$ & $-0,52$ & $-0,30$ & ----- & ----- & ----- & & & \\
\hline$A$ & $-0,16$ & $-0,23$ & 0,02 & 0,53 & 0,50 & 0,19 & ----- & ----- & ----- \\
\hline M & 0,05 & $-0,22$ & 0,08 & 0,27 & 0,45 & 0,10 & 0,38 & 0,48 & 0,31 \\
\hline
\end{tabular}

Estudo $1^{a}=\left(\right.$ McConnaughy et al. (1983) $(N=155)$. Estudo $2^{b}=$ McConnaughy \& DiClemente (1989) $(N=327)$. Atual $^{c}=(\mathrm{N}=147$ para $P C, C$ e $A ; N=146$ para $M)$.

$\mathrm{PC}^{\mathrm{d}}=$ Pré-Contemplação; $\mathrm{C}=$ Contemplação; $\mathrm{A}=\mathrm{Ação;} \mathrm{M}=$ Manutenção.

Tabela 5. Coeficientes de correlação de Spearman entre a EEM ${ }^{1}$ e EDAO- $R^{2} \quad(N=76)$.

\begin{tabular}{lccc}
\hline Estágio & AR & Pr & Adaptação Geral \\
Pré contemplação & $-0,17$ & 0,00 & $-0,07$ \\
Contemplação & 0,00 & 0,09 & 0,02 \\
Ação & 0,07 & $0,22^{*}$ & $0,21^{*}$ \\
Manutenção & $-0,07$ & 0,13 & 0,10 \\
\hline
\end{tabular}

1 = Escala de Estágios de Mudança.

2 = Escala Diagnóstica Adaptativa Operacionalizada-Redefinida.

"significante ao nível de 0,05 (bi-caudal). 
Tabela 6. Médias, desvios padrão, valores mínimos e máximos para os grupo que concluiu a psicoterapia breve, interrompeu e para o total de pacientes atendidos.

\begin{tabular}{|c|c|c|c|c|c|c|c|c|c|c|c|c|}
\hline \multirow[b]{2}{*}{ Estágio } & \multicolumn{4}{|c|}{ Concluiu (N = 35) } & \multicolumn{4}{|c|}{ Interrompeu $(\mathrm{N}=28)$} & \multicolumn{4}{|c|}{ Total $(\mathrm{N}=63)$} \\
\hline & M & DP & Mín. & Max. & M & DP & Mín. & Max. & $M$ & DP & Mín. & Max. \\
\hline PC & 1,81 & 0,59 & 1,00 & 3,00 & 1,73 & 0,63 & 1,00 & 3,25 & 1,77 & 0,60 & 1,00 & 3,25 \\
\hline C & 4,78 & 0,31 & 3,83 & 5,00 & 4,81 & 0,27 & 4,00 & 5,00 & 4,80 & 0,29 & 3,83 & 5,00 \\
\hline A & 3,92 & 0,74 & 1,78 & 5,00 & 3,94 & 0,86 & 2,00 & 5,00 & 3,93 & 0,79 & 1,78 & 5,00 \\
\hline$M$ & 3,62 & 0,66 & 2,22 & 4,78 & 3,72 & 0,83 & 2,11 & 5,00 & 3,66 & 0,74 & 2,11 & 5,00 \\
\hline
\end{tabular}

Tabela 7. Análise de variância investigando as diferenças entre médias nos estágios entre os que concluíram e os que interromperam a psicoterapia breve.

\begin{tabular}{llrcccc}
\hline Estágio & Fonte & SQs & gl & MQ & $F$ & P \\
\hline PC & Entre & 0,09 & 1 & 0,09 & 0,24 & 0,63 \\
& Dentro & 22,50 & 61 & 0,37 & & \\
CT & Total & 22,59 & 62 & & & \\
& Entre & 0,01 & 1 & 0,01 & 0,16 & 0,69 \\
& Dentro & 5,22 & 61 & 0,08 & & \\
A & Total & 5,23 & 62 & & & \\
& Entre & 0,01 & 1 & 0,01 & 0,01 & 0,90 \\
& Dentro & 38,81 & 61 & 0,63 & & \\
M & Total & 38,82 & 62 & & & 0,60 \\
& Entre & 0,15 & 1 & 0,15 & 0,28 & \\
& Dentro & 33,57 & 61 & 0,55 & & \\
& Total & 33,73 & 62 & & & \\
\hline
\end{tabular}

A análise de variância (Tabela 7) efetuada uma para cada estágio, tendo com variável independente a distinção concluiu/interrompeu e, variáveis dependentes, cada um dos estágios, confirma que as diferenças observadas na Tabela 6 não são significantes.

\section{DISCUSSÃO}

Apesar da restrição que se possa fazer ao tamanho da amostra, este primeiro estudo de validade da versão em português da Escala dos Estágios de Mudança revelou estrutura fatorial muito semelhante à da versão em inglês, em que quatro componentes, correspondentes aos estágios de mudança, pré-contemplação, contemplação, ação e manutenção, são claramente configurados.

Uma explicação possível seria a maneira como a escala foi construída. Conforme referido, surgiu da experimentação prévia de seus autores, interessados em compreender como as pessoas 
tentam mudar comportamentos de dependência ao álcool e tabaco por si mesmas, ou dentro de programas profissionais de tratamento (DiClemente \& Prochaska,1982; Prochaska \& DiClemente,1983).

Passando à análise dos itens de cada estágio, os resultados sugerem que:

1. Para o estágio de pré-contemplação, a substituição do item 11 pelo 24 é uma possibilidade para a versão em português. Ainda que o item 24 tenha apresentado maior carga no estágio de manutenção, o seu enunciado parece representar mais adequadamente o de pré-contemplação, devendo-se portanto retê-lo neste estágio, até que novas pesquisas sejam empreendidas.

2. Para o estágio de contemplação, os resultados sugerem a necessidade de adaptação ou construção de, ao menos, um item, uma vez que sete se encontram adequadamente representados. Seriam os itens 8, 12, 15,19 e 21 , que representam este estágio na escala original, além do item 11, que apresentou correlação negativa suficiente e o 20, com maior carga neste fator do que no de ação, como na versão original.

Numa primeira tentativa talvez se deva pensar em reformular os enunciados dos itens 2 e 4, tentando dar-lhes uma redação mais coloquial. No caso do item 2, é possível que a expressão auto-aperfeiçoamento não tenha sido bem compreendida pelos participantes. E quanto ao item 4, o uso do subjuntivo do verbo valer pode também ter dado margem a um certo "estranhamento", apesar de o nível educacional da amostra ter sido relativamente alto para o padrão de paciente institucional brasileiro.

3. O componente correspondente ao estágio de ação foi o que apresentou maior número de itens com alta carga fatorial, o que contribui, naturalmente, para o alto nível de consistência interna observado. Apesar de todos os itens originais também se mostrarem representados na versão em português, sugere-se a troca do item 20 pelo 2, já que este último, além de apresentar maior covariância com este fator, também apresenta maior validade aparente.

4. Quanto ao estágio de manutenção, sete dos oito itens originais também se mantêm representados aqui. Apenas o item 9 não apresentou carga suficiente. Talvez, substituindo-se a expressão "trabalhar no meu problema" por "enfrentar minhas dificuldades" torne mais claro ao paciente a idéia subjacente.

No que diz respeito à independência das medidas de cada estágio, os resultados confirmaram a expectativa teórica, apesar dos coeficientes de correlação inferiores aos dos estudos anteriores, como se viu na Tabela 4. A associação negativa entre o estágio de contemplação e pré-contemplação mostra que os itens medem atitudes diferentes perante ao problema. Efetivamente, enquanto no primeiro existe a consciência do problema e a aceitação da necessidade de enfrentá-lo, no segundo prevalece a negação destas duas condições. Já para os de contemplação e ação, ou ação e manutenção, a associação positiva era esperada, pois ambos implicam a consciência do problema acompanhada de seu enfretamento. Por outro lado, o índice relativamente baixo de associação indica que eles não se superpõem totalmente, constituindo constructos algo diferentes entre si.

A consistência interna dos itens de cada estágio foi inferior para a pré-contemplação e contemplação, refletindo possivelmente a menor covariância dos itens com estes fatores se comparados aos de ação e manutenção. Além disto, ela se apresentou inferior aos valores obtidos nos estudos originais nos quatro estágios de mudança, indicando a necessidade de revisão e adaptação dos itens na versão em português.

No que concerne à medida de validade concorrente, a quase ausência de associação entre os estágios de mudança pré-contemplação, contemplação e manutenção e a adequação na adaptação geral aponta para relativa independência entre as medidas efetuadas. Neste sentido, na avaliação de pacientes que buscam psicoterapias deve-se tratar estas duas medidas 
de maneira independente, não presumindo que elas possam se substituir.

Antes porém de se adotar como conclusivas estas observações, deve-se proceder a novas pesquisas, já que a associação negativa, ainda que não significante, entre o estágio de pré-contemplação e o setor AR está de acordo com a expectativa teórica, pois considera-se que melhor adequação adaptativa deva favorecer a aceitação de um problema e a disposição para seu enfrentamento, o que é contrário ao estágio de pré-contemplação. Da mesma forma, uma associação positiva entre o estágio de ação e a adequação da Pr revela que os indivíduos com melhor adaptação no setor produtivo são também aqueles empenhados em enfrentar suas dificuldades na psicoterapia. Uma melhor adequação da adaptação no setor da Pr reflete-se na adaptação geral, que também evidenciou associação significante com o estágio de ação.

Os resultados parcialmente concernentes com o esperado teoricamente podem ser apenas uma peculiaridade desta amostra ou podem estar expressando uma relação entre as duas medidas que precisaria ser melhor compreendida. Por ora, sugere-se cautela na interpretação destes resultados e que as pesquisas futuras utilizem outros critérios na investigação de validade concorrente.

No que concerne à validade preditiva, os resultados sugerem que, apenas com base no estágio de mudança do início da psicoterapia, não se pode distinguir os pacientes que irão concluí-la ou não. Ou seja, a EEM não possui valor preditivo em relação à condição do término de psicoterapias psicodinâmicas breves, com populações clínicas com perfil semelhante à estudada.

Da mesma forma que para a validade simultânea, sugerem-se novas pesquisas de validade preditiva da EEM envolvendo outras variáveis de critério. Pode-se, por exemplo, estimar a validade preditiva da EEM junto a outras populações em que a versão original da escala já demonstrou valor preditivo como, por exemplo, fumantes, alcoólicos, obesos, entre outros.

Mesmo para psicoterapias psicodinâmicas breves, outros critérios como, por exemplo, a evolução para outros estágios de mudança em terapias bem sucedidas e a falta de mudança nas consideradas mal sucedidas, podem levar a resultados diferentes dos aqui encontrados.

\section{CONCLUSÕES}

Apesar do tamanho reduzido da amostra utilizada, este primeiro estudo de validação de constructo da versão em português da Escala dos Estágios de Mudança reproduziu a estrutura fatorial encontrada em dois estudos anteriores, em que a versão em inglês foi avaliada. Adaptações em quatro dos 32 itens deverão ser testadas em pesquisas futuras, para conferir maior validade de constructo à versão em portuguêse, eventualmente, ampliar a consistência interna dos componentes.

Além disto, novos estudos de validade concorrente e preditiva, utilizando outros critérios, devem ser realizados.

\section{REFERÊNCIAS BIBLIOGRÁFICAS}

DICLEMENTE, C. C., \& PROCHASKA, J. O. (1982). Self-change and therapy change of smoking behavior: A comparison of processes of change in cessation and maintenance. Addictive Behavior, 7, 133-142.

GARFIELD, S. L. (1986). Research on client variables in psychotherapy. Em S. L. GARFIELD \& A. E. Bergin (Orgs.), Handbook of psychotherapy and behavior change ( $3^{a}$ ed., pp. 213-256). New York: John Wiley \& Sons.

HUSBY, R. (1985). Short-term psychotherapy III. A 5-year follow-up of 36 neurotic patients. Psychotherapy \& Psychosomatics, 43, 17-22. 
MALAN, D. H. (1981). As fronteiras da psicoterapia breve ( L. Knijnik \& M. E. Z. Schestatsky, Trads.). Porto Alegre: Artes Médicas. (Trabalho original publicado em 1976).

MCCONNAUGHY, E. A., DICLEMENTE, C. C., PROCHASKA, J. O., \& Velicer, W. F. (1989). Stages of Change in psychotherapy: a followup report. Psychotherapy, 26, 494-503.

MCCONNAUGHY, E. A., PROCHASKA, J. O., \& VELICER, W. F. (1983). Stages of Change in psychotherapy: Measurement and samples profiles. Psychotherapy, 20, 368-375.

NORCROSS, J., Prochaska, J., \& Hambrecht, M. (1985). The Levels of Attribution and Change (LAC) Scale: Development and measurement. Cognitive Therapy and Research, 9, 631-649.

PACE, R. (1999). Escala de Estágios de Mudança: variáveis psicométricas. Dissertação de Mestrado, Pontifícia Universidade Católica de Campinas, Campinas.

PROCHASKA, J. O. (1995). An ecletic integrative approach: transtheoretical therapy. Em A. S. Gurman \& S. B. Messer (Orgs.), Essential psychotherapies: theory and practice (pp. 403-440). New York: The Guilford Press.

PROCHASKA, J. O., \& DICLEMENTE, C. C. (1983). Stages and processes of self-change in smoking: Toward an integrative model of change. Journal of Consulting and Clinical Psychology, 5, 390-395.

PROCHASKA, J. O., \& NORCROSS, J. C. (1999). Systems of psychotherapy: a transtheoretical analysis. Pacific Grove: Brooks/ Cole Pub. Co.

PROCHASKA, J. O., VELICER, W. F., DICLEMENTE, C. C. \& Fava, J. (1988). Measuring processes of change: Applications to the cessation of smoking. Journal of Consulting and Clinical Psychology, 56, 520-528.

SIFNEOS, P. (1989). Psicoterapia dinâmica breve: avaliação e técnica. (A. E. Fillmann, Trad.) Porto Alegre: Artes Médicas (Trabalho original publicado em 1987).

SIMON, R. (1989). Psicologia clínica preventiva: novos fundamentos. São Paulo: EPU.

SIMON, R. (1997). Proposta de redefinição da EDAO (Escala Diagnóstica Adaptativa Operacionalizada). Boletim de Psicologia, XLVII (107), 85-94.

YOSHIDA, E. M. P. (1999). EDAO-R: precisão e validade. Mudanças Psicoterapia e Estudos Psicossociais, 7 (11), 189-213.

Recebido para publicação em 14 de maio de 2003 e aceito em 14 de setembro de 2003. 
